\title{
Effect of Mouthwashes on Frictional Properties of Gold-plated and Ordinary Stainless Steel Orthodontic Brackets
}

\author{
${ }^{1}$ Noor M Garma, ${ }^{2}$ Hiba M Hussien, ${ }^{3}$ Mohammed Nahidh
}

\begin{abstract}
Background: This study aimed to evaluate and compare the static frictional forces between the gold-plated and conventional stainless steel brackets following immersion in three types of mouthwashes.
\end{abstract}

Materials and methods: Eighty orthodontic brackets (40 stainless steel and 40 gold-plated) were divided equally into four subgroups and dipped in $15 \mathrm{~mL}$ of different mouthwashes for 45 days. The mouthwashes included chlorhexidine, aloe vera, aloe vera with fluoride and distilled water as a control group. The brackets then attached to an experimental model consisted of acrylic block. Frictional resistance was measured on $0.019 \times$ 0.025 inch stainless steel archwires using Tinius Olsen Instron universal testing machine. Independent sample t-test and one way ANOVA were used to analyze the collected data.

Results: Gold-plated brackets showed high significant friction in comparison with stainless steel one in all mouthwashes. In both types of brackets, there was a statistically highly significant difference among different mouthwashes. Aloe vera mouthwash showed the highest friction with steel brackets while Chlorhexidine had a maximum effect on the frictional force with gold-plated bracket.

Conclusion: During orthodontic treatment and when sliding mechanics with minimum friction is required, the orthodontist should prescribe fluoridated herbal mouth rinse with Goldplated brackets. Chlorhexidine should be excluded due to exaggerated frictional resistance that may impede or delay the intended tooth movement, from the same point of view, when using stainless steel brackets, chlorhexidine is the best mouth rinse, while herbal mouth rinse without fluoride (aloe vera mouthwash) is contraindicated.

Clinical significance: Orthodontists should take care of prescribing mouth rinses to decrease their effects on the friction.

Keywords: Chlorhexidine, Friction, Gold-plated brackets, Herbal mouth rinse.

How to cite this article: Garma NM, Hussien HM, Nahidh M. Effect of Mouthwashes on Frictional Properties of Gold-plated and Ordinary Stainless Steel Orthodontic Brackets. World J Dent 2018;9(6):489-494.

Source of support: Nil

Conflict of interest: None

${ }^{1-3}$ Department of Orthodontics, College of Dentistry, University of Baghdad, Baghdad, Republic of Iraq

Corresponding Author: Mohammed Nahidh, Department of Orthodontics, College of Dentistry, University of Baghdad, Baghdad, Republic of Iraq, Phone: +009647702551616, e-mail: m_nahidh79@yahoo.com

\section{INTRODUCTION}

Friction during fixed orthodontic treatment is generated by the relative motion between the archwire and bracket. This friction must be overcome before force can be transferred from the orthodontic device to the teeth. ${ }^{1,2}$ It is essential for orthodontists to identify the exact frictional forces run into the bracket-wire interface because optimum force had to be applied to provoke the proper biologic response for proficient tooth movement. ${ }^{2}$ Frictional forces are of two types: a static frictional force which is the force desired to initiate the relative sliding of two surfaces; it restrains the tooth movement. Friction is diminished and movement began when the elastically deformed wire uprights the tooth. The other type is the kinetic frictional force which occurs when the tooth moves in the direction of the force application ${ }^{3}$ and can be defined as the component of friction that has to be overcome to continue the motion or the force that counteracts motion.

Teeth movement along the archwire occurred in a series of incredibly short steps or jumps, i.e., not continuous, so the static friction presented great importance to be overcome each time the tooth moved a little. ${ }^{4}$ It had been stated that friction occurred between archwire and bracket may lead to loss of force up to $50 \%{ }^{3}$

A huge number of innovative orthodontic materials and manufacturing techniques have been used as an alternative to the classical stainless steel wires and brackets. Nevertheless, frictional forces must be anticipated for every new combination of archwires and brackets so as to envisage their performance when they are used in clinical applications. ${ }^{1}$

To compare the friction performance for various combinations of bracket/archwire contacts, it is important to consider a number of factors including: the material types of brackets and archwires, relative bracket-wire clearance, size of the archwire, archwire cross-section (round or rectangular), torque at the bracket-archwire interface, surface conditions of the archwires and bracket slot, and type and force of ligation, saliva is a supplementary factor that may affect friction. ${ }^{5,6}$

It is challenging to adequately educate, train and encourage patients to remove plaque solely by mechanical means of plaque control as it requires time, motivation and manual skill ${ }^{7}$ which is especially true with fixed 
orthodontic appliances in whom a high plaque accumulation has been described, ${ }^{8}$ therefore, in addition to mechanical plaque control methods, chemical plaque control using mouthwashes is essential to dental patients by orthodontists and other oral health care providers to help maintain oral health throughout treatment when oral hygiene might be compromised. ${ }^{9}$

Clinically, antiseptic mouth rinses are used to reduce the accumulation of plaque during the active phase of orthodontic treatment. ${ }^{10}$ However, some of their constituents may lead to corrosion and discoloration of stainless steel and titanium alloys. Corrosion and its end product that rising surface roughness have a prospective effect of increasing the frictional force at the wire-bracket interface. Resistance to corrosion of stainless steel and titanium archwires depends primarily on the development of an inactive oxide layer. When this layer deteriorates, the archwire will be undergoing corrosion. ${ }^{11}$

The effect of mouth rinses on the ions release from various combinations of archwires and brackets had been reported by many researchers. ${ }^{12-14}$ The uniqueness of this study is that it has been the first one that tests the frictional forces produced by gold-plated orthodontic brackets under the mouthwash challenge compared to the former classical stainless steel brackets in an attempt to be able to choose the most biocompatible bracket/ mouthwash combination in the clinical practice.

\section{MATERIALS AND METHODS}

Eighty maxillary premolar brackets were divided into two groups according to their manufacturing types; 40 stainless steel brackets (Votion ${ }^{\mathrm{TM}}$ ) and 40 gold-plated brackets (Marquis TruGold ${ }^{\mathrm{TM}}$ ). All of these brackets were used in this study in as-received condition, Roth prescription, 0.022-inch slot and from the same company (Orthotechnology, USA).

The brackets were randomly divided into four numerically equal subgroups according to the mouthwash they dipped in. Three types of mouthwash were chosen because of their commercial availability and identical application methods:

- Zordyl ${ }^{\circledR}$ mouthwash $(\mathrm{CHX})\left(\right.$ Julphar $^{\circledR}$, United Arab Emirates), containing Chlorhexidine gluconate $0.2 \%$ w/v, pH: 7.10

- Aloe Dent ${ }^{\circledR}$ mouthwash (ALO) (Aloe Vera mouthwash, Optima $^{\circledR}$, Italy) contains natural Aloe Vera ingredient Aqua, Aloe Barbardensis, Sorbitol, Polysorbate 20, Citrus Grandis (grapefruit), Seed extract, Menthapipenta oil, Sodium Lauroyl Sarcosinate, Aroma, Menthol, Melaleuca Altemifolia Oil, Escin (Horse Chestnut), Centtella Asiatica, Xylitol, Sodium Hydroxymethylglycinate, Citric Acid, CI 75810. Limonene, Linalool, Natural constituent of essential oils, pH: 5.17
- Aloe Dent ${ }^{\circledR}$ mouthwash with fluoride(ALOF) (Aloe Vera mouthwash with fluoride, Optima ${ }^{\circledR}$, Italy), contains the same constituent of Aloe Dent ${ }^{\circledR}$ in addition to Sodium Monofluorophosphate (Fluoride 1500 ppm), pH: 5.46.

Distilled water (D.W.), Iraq, pH: 7.04

Each bracket was individually dipped in $15 \mathrm{~mL}$ of mouthwash in $20 \mathrm{~mL}$ glass capped container and incubated at a constant temperature of $37^{\circ} \mathrm{C}$ for 45 days. Several studies have demonstrated that the levels of metal release from fixed orthodontic appliances peak at day 7 and that all release is completed within 4 weeks. ${ }^{15,16}$

To test the effect of mouthwashes on the frictional properties of the Votion and TruGold brackets type, all of the brackets were attached to an experimental model consisted of the acrylic block ( $3 \mathrm{~cm}$ length, $1.2 \mathrm{~cm}$ width, and $1.7 \mathrm{~cm}$ thickness). A section of $0.0215 \times 0.025$-inch straight stainless steel archwire was used to align the bracket on the acrylic block, ${ }_{1}^{17}$ and then the brackets were fixed over acrylic by the light-cured composite.

A total of 80 pieces of archwire measuring $4 \mathrm{~cm}$ in length were cut from the straight portion of $0.019 \times 0.025$-inch stainless steel archwires (Orthotechnology, USA) and randomly divided into eight subgroups (10 per each subgroup).

Each testing archwire was seated in the slot of the bracket after it was degreased with ethanol to remove oil, debris, and dirt because they may affect the frictional resistance, ${ }^{18,19}$ and ligated using conventional clear elastomeric modules (Orthotechnology, USA).

Frictional properties were measured with a universal testing machine (Instron H50KT Tinius Olsen testing machine, England with $10 \mathrm{~N}$ load cell). A computer connected to the testing machine displayed a graph showing ultimate force variation and recorded the tensile force produced on every $0.01 \mathrm{~mm}$ distance. The tensile force needed to slide $12 \mathrm{~mm}$ of the archwire over the test specimen bracket for two minutes at a speed of six mm per minute, was measured (Fig. 1). Graphs from each sample

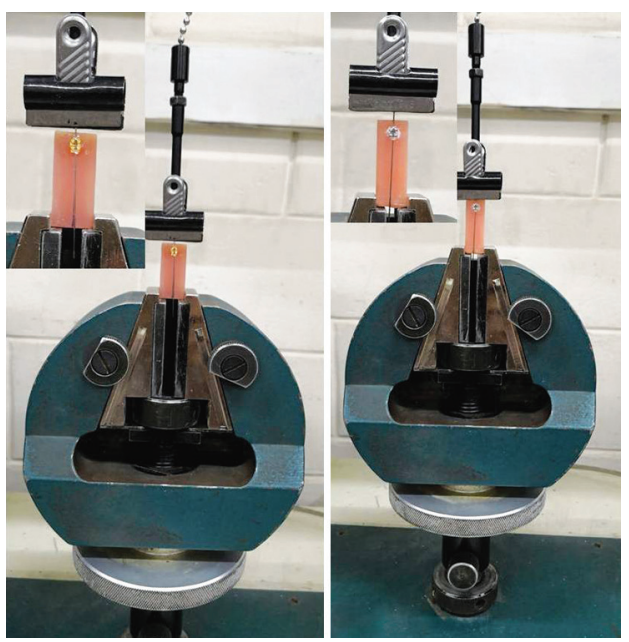

Fig. 1: Frictional resistance test for gold-plated bracket (left side), and for stainless steel brackets (right side) 
were analyzed to determine the primary tensile strength peak of the tested archwire in Newton for every traction test that was converted into grams then after. This represented the maximum frictional resistance force required to initiate movement of the archwire through the bracket (static friction). ${ }^{20,21}$

Each bracket/mouthwash combination was submitted once to the tensile test and the test was performed 10 times by a single operator for each subgroup, thus totalizing 40 mechanical testing for each group of brackets and eighty for both brackets groups.

\section{Statistical Analysis}

The collected data were managed statistically using SPSS (statistical package of social sciences) software version 24. The following types of statistics were used in this study:

Descriptive statistics: including means, standard deviations, minimum and maximum values.

- Inferential statistics: including:

- Independent sample t-test: For comparison the friction between the two types of brackets in each medium.
- One-way ANOVA test: For comparison friction among different media.

- Tukey's honestly significant difference (HSD) test: To test any statistically significant difference between every two types of media.

In the statistical evaluation, the following levels of significance are used:
- $p>0.05$
- $\quad p$ between $\geq 0.05$ and $p>0.01$
- $p \leq 0.01$

Nonsignificant Significant Highly significant

\section{RESULTS}

Table 1 demonstrated the descriptive statistics of the static friction of different types of brackets in each brand of mouthwashes. In general, gold-plated brackets showed high significant friction in comparison with steel one in all mouthwashes.

Studying the effect of different mouthwashes on the static friction of stainless steel and gold-plated brackets was demonstrated in Tables 2 and 3. In both types of brackets, there was a statistically highly significant dif-

Table 1: Effect of brackets types on the static frictional force in different mouthwashes

\begin{tabular}{|c|c|c|c|c|c|c|c|}
\hline \multirow[b]{2}{*}{ Media } & \multirow[b]{2}{*}{ Bracket types } & \multicolumn{4}{|c|}{ Descriptive statistics } & \multicolumn{2}{|c|}{ Comparison } \\
\hline & & Mean & $S D$ & Min. & Max. & $t$-test & $p$ value \\
\hline \multirow[t]{2}{*}{ D.W. } & Gold & 73.837 & 3.404 & 69.806 & 78.776 & -9.728 & 0.000 \\
\hline & Votion & 55.733 & 2.393 & 52.857 & 59.327 & & \\
\hline \multirow[t]{2}{*}{$\mathrm{CHX}$} & Gold & 209.749 & 1.966 & 207.041 & 211.939 & -92.585 & 0.000 \\
\hline & Votion & 62.659 & 2.959 & 58.776 & 66.633 & & \\
\hline \multirow[t]{2}{*}{ ALOF } & Gold & 105.424 & 2.780 & 102.245 & 109.918 & -10.660 & 0.000 \\
\hline & Votion & 84.347 & 3.437 & 80.561 & 89.816 & & \\
\hline \multirow[t]{2}{*}{ ALO } & Gold & 195.825 & 3.965 & 190.204 & 199.592 & -49.180 & 0.000 \\
\hline & Votion & 96.374 & 2.174 & 94.184 & 99.898 & & \\
\hline
\end{tabular}

Table 2: Effect of various mouthwashes on the static frictional force in each bracket type

\begin{tabular}{|c|c|c|c|c|c|c|c|}
\hline \multirow[b]{2}{*}{ Bracket types } & \multirow[b]{2}{*}{ Media } & \multicolumn{4}{|c|}{ Descriptive statistics } & \multicolumn{2}{|c|}{ Comparison } \\
\hline & & Mean & $S D$ & Min. & Max. & F-test & $p$ value \\
\hline \multirow{4}{*}{ Gold } & D.W. & 73.837 & 3.404 & 69.806 & 78.776 & \multirow{4}{*}{2296.253} & \multirow{4}{*}{0.000} \\
\hline & $\mathrm{CHX}$ & 209.749 & 1.966 & 207.041 & 211.939 & & \\
\hline & ALOF & 105.424 & 2.780 & 102.245 & 109.918 & & \\
\hline & ALO & 195.825 & 3.965 & 190.204 & 199.592 & & \\
\hline \multirow{4}{*}{ Votion } & D.W. & 55.733 & 2.393 & 52.857 & 59.327 & \multirow{4}{*}{229.397} & \multirow{4}{*}{0.000} \\
\hline & $\mathrm{CHX}$ & 62.659 & 2.959 & 58.776 & 66.633 & & \\
\hline & ALOF & 84.347 & 3.437 & 80.561 & 89.816 & & \\
\hline & ALO & 96.374 & 2.174 & 94.184 & 99.898 & & \\
\hline
\end{tabular}

Table 3: Tukey's HSD test after ANOVA test

\begin{tabular}{lllllll}
\hline & & \multicolumn{3}{c}{ Gold } & & \multicolumn{2}{c}{ Votion } \\
\cline { 3 - 4 } \cline { 6 - 7 } Media & & Mean difference & $p$-value & & Mean difference & $p$ value \\
\hline D.W. & CHX & -135.912 & 0.000 & & -6.927 & 0.006 \\
& ALOF & -31.588 & 0.000 & & -28.614 & 0.000 \\
& ALO & -121.988 & 0.000 & & -40.641 & 0.000 \\
\hline \multirow{2}{*}{ CHX } & ALOF & 104.325 & 0.000 & & -21.688 & 0.000 \\
& ALO & 13.924 & 0.000 & & -33.714 & 0.000 \\
\cline { 6 - 7 } & ALO & -90.400 & 0.000 & & -12.027 & 0.000 \\
\hline
\end{tabular}


ference among different mouthwashes. ALO showed the highest friction with steel brackets while Chlorhexidine had a maximum effect on the frictional force with goldplated bracket.

Tukey's HSD test revealed a highly significant difference between every two types of mouthwashes in both bracket types.

\section{DISCUSSION}

The final results of orthodontic treatment depend to a large extent on how will the forces and the consequential reactions be controlled and whether sliding movements between brackets and archwires are required in orthodontics. Friction is created between the sliding surfaces and has a major impact on the force ultimately delivered to the teeth, therefore friction is considered as an important determining factor of the final outcome in orthodontics. ${ }^{22}$

According to Eliades and Brantley, ${ }^{23}$ there are two methods used to determine the frictional properties of orthodontic archwires: first by measuring the roughness of the tested bracket's slot in addition to study morphology of the archwires surface prior and after the sliding on the brackets slot and, second by real simulation of sliding at a given distance using a mechanical testing machine (Instron) with custom-made assemblies under different bracket-wire engagement modes.

This study measured the frictional forces of two types of orthodontic brackets when exposed to various types of mouthwashes as plaque control measures using an Instron universal testing machine with the custom-made assembly in dry condition.

Although stainless steel brackets were widely tested regarding frictional forces, yet up to date, there was no former study determined which mouth rinse is the best when using gold-plated brackets during orthodontic treatment stages concerning these forces. In this study, two types of brackets were used: gold-plated brackets (stainless steel brackets plated with $24 \mathrm{~K}$ gold of one piece) and Votion brackets (two pieces stainless steel). The brackets were immersed in mouthwash for 45 days, as this period represented approximately the period of contact between the brackets and mouthwash during two years of fixed orthodontic treatment. ${ }^{24}$ The mouthwashes used were: chlorhexidine, aloe vera mouthwash with fluoride, aloe vera mouthwash without fluoride, and distilled water.

Static friction is the friction force component that must be overcome to initiate motion, it also can be defined as while kinetic friction is the component of friction that has to be overcome to maintain motion, or in other words, it is the force that resists motion during orthodontic tooth movement. ${ }^{4}$ The determination of static and kinetic fric- tion can be difficult and misleading because they are dynamically interrelated, especially at very low sliding velocity. ${ }^{25}$

From a clinical point of view, static friction is always greater than kinetic friction and is considered to be more important ${ }^{26}$ as it is harder to change a body from its initial situation than to maintain it moving as a force is applied to an object; and since the merit of tooth movement along an archwire is a step-like series, static friction is considered to be more valuable than kinetic friction in orthodontics, ${ }^{22}$ hence the static friction generated between the brackets and archwires during sliding movement was chosen to be measured in this study.

Concerning brackets types, gold-plated brackets showed higher frictional forces than stainless steel brackets in all immersed and control groups. In spite of the presence of the exterior protective gold layer which is plated originally on one piece casted steel bracket to enhance resistant to wear, chipping and peeling, ${ }^{27}$ results elucidating that this layer was not stable under the mouth rinses being used in the present study.

In one recent study ${ }^{27}$ that examined the ions release from stainless steel and gold-plated brackets after immersion in different herbal mouthwashes, no subtle pattern between bracket types and concentration of cations released could be seen, and consequently this could not be clear-cut cause and effect relationship, instead results might be due to the effect of cold working (bending, shearing, punching, etc.). A non-uniform deformation could be happened during the manufacturing process of gold-plated brackets, moreover; unequal cooling from high temperature lead to internal structure rearrangements involving volume change causing internal stress that may produce cracks of the outer protective layer, accelerating corrosion ${ }^{28}$ and consequently increase the surface roughness which is a critical variable in determining friction since the smoothest surface is expected to yield the lowest friction and vice versa. ${ }^{1}$

In addition, strong adherence of the gold film to steel would produce shearing that naturally leads to a higher friction coefficient and shorter wear life, ${ }^{29}$ furthermore; the presence of irregularities in the floor surface of the bracket's slot will increase the pressure applied by the arch wire onto the few small peaks (asperities) leading to abrasion throughout tooth sliding movements, so it is recommended that the materials of the brackets should have ample stiffness and hardness to defy the morphologic deformation associated with frictional forces through tooth sliding movements. ${ }^{30}$

Among gold-plated brackets subgroups, gold-plated brackets immersed in aloe vera with fluoride showed the lowest frictional forces making aloe vera with fluoride mouthwash to be the most recommended mouth rinse 
with this bracket type. This was interesting since fluoride showed higher corrosive ability in previous studies ${ }^{24,27}$ while the highest static friction was recorded in goldplated brackets immersed in chlorhexidine group, this could be consistent with other researches describing the corrosive ability of chlorhexidine. ${ }^{24,31}$

Considering Votion brackets subgroups, the highest static friction was measured in aloe-vera mouthwash group. This is consistent with another study compared ion release among mouthwashes. ${ }^{27}$ Aloe-Vera herb showed the highest manganese and copper ions which are considered as main components of stainless steel alloy, detecting surface corrosion of the metal and consequently increase surface roughness and friction. These results disagreed with Singh $^{32}$ who claimed that herbal mouth rinses showed inhibition efficiency of corrosion lied between $22 \%$ and $73 \%$ at different concentrations.

Contrary to other researchers ${ }^{33-35}$ who claimed that fluoride-containing agents have fluoride ions and $\mathrm{pH}$ between 3.5 and 7 which may damage the oxidized layer formed on the steel surfaces and causes corrosion and roughness, the results of the current study revealed that adding Fluoride to Aloe Vera herbal mouth rinse (aloe vera with fluoride) significantly decreased the static frictional resistance, which might be due to the copious herbal ingredients of this mouth rinse. It consisted of 75 nutrients including vitamins, sugar, enzymes, lignin phenolic compounds, sterols, saponins, amino acids, salicylic acid and minerals such as $\mathrm{Ca}, \mathrm{Mn}, \mathrm{Na}, \mathrm{K}, \mathrm{Cu}, \mathrm{Mg}, \mathrm{Z}$, $\mathrm{Cr}$ and $\mathrm{Fe} .{ }^{36}$ These variant substances may suppress the corrosive ability of fluoride anion by chemical combination of positively charged ions (cations) with negatively charged fluoride ion, so adding fluoride to herbal mouth rinse would have a positive impact on the final results of orthodontic treatment whether the brackets used are stainless steel or gold-plated.

The major limitation of the present study was being an in-vitro study and the laboratory data might not reflect the clinical situations regarding the effect of saliva, food, and beverages, etc., and yet, these data aimed to interpret comparatively the effect of different mouthwashes on the frictional properties of two types of orthodontic brackets.

\section{CONCLUSION}

Based on the results of this study and considering frictional resistance during clinical practice, whenever sliding mechanics is needed using gold-plated brackets, the orthodontist should consider the use of fluoridated herbal mouth rinse. Chlorhexidine should be excluded because it exaggerated the frictional resistance that may impede or delay the required tooth movement. On the other hand, Chlorhexidine is the best mouth rinse if the brackets used are votion stainless steel type, while herbal mouth rinse without fluoride (aloe vera mouthwash) is contraindicated.

\section{REFERENCES}

1. Carrion-Vilches FJ, Bermudez MD, Fructuoso P. Static and kinetic friction force and surface roughness of different archwire- bracket sliding contacts. Dent Mater J 2015;34(5): 648-653.

2. Zhang H, Guo S, Wang D, Zhou T, Wang L, Ma J. Effects of nanostructured, diamond like, carbon coating and nitrocarburizingon the frictional properties and biocompatibility of orthodontic stainless steel wires. Angle Orthod 2016; 86(5):782-788.

3. Wichelhaus A, Geserick M, Hibst R, Sander FG. The effect of surface treatment and clinical use on friction in NiTi orthodontic wires. Dent Mater 2005;21(10):938-945.

4. Frank CA, Nikolai RG. A comparative study of frictional resistances between orthodontic bracket and arch wire. Am J Orthod 1980;78(6):593-609.

5. Cacciafesta V, Sfondrini MF, Scribante A, Klersy C, Auricchio F. Evaluation of friction of conventional and metal-insert ceramic brackets in various bracket-archwire combinations. Am J Orthod Dentofacial Orthop 2003;124(4):403-409.

6. Kusy RP, Whitley JQ, Mayhew MJ, Buckthal JE. Surface roughness of orthodontic archwires via laser spectroscopy. Angle Orthod 1988;58(1):33-45.

7. DePaola LG, Spolarich AE. Safety and efficacy of antimicrobial mouthrinses in clinical practice. J Dent hygiene 2007; 81(5):1-16.

8. Sukontapatipark W, El-Agroudi MA, Selliseth NJ, Thunold K, Selvig KA. Bacterial colonization associated with fixed orthodontic appliances. A scanning electron microscopy study. Eur J Orthod 2001;23(5):475-484.

9. Larrabee TM, Liu SS, Torres-Gorena A, Soto-Rojas A, Eckert GJ, Stewart KT. The effects of varying alcohol concentrations commonly found in mouth rinses on the force decay of elastomeric chain. Angle Orthod 2012;82(5):894-899.

10. Brightman LJ, Terezhalmy GT, Greenwell H, Jacobs M, Enlow $\mathrm{DH}$. The effect of a $0.12 \%$ chlorhexidine gluconate mouthrinse on orthodontic patients aged 11 through 17 with established gingivitis. Am J Orthod Dentofacial Orthop 1991;100(4):324-329.

11. Grímsdóttir MR, Hensten-Pettersen A, Kullmann A. Proliferation of nickel-sensitive human lymphocytes by corrosion products of orthodontic appliances. Biomaterials 1994; 15(14):1157-1160.

12. Walker MP, Ries D, Kula K, Ellis M, Fricke B. Mechanical properties and surface characterization of beta titanium and stainless steel orthodontic wire following topical fluoride treatment. Angle Orthod 2007;77(2):342-348.

13. Tahmasbi S, Ghorbani M, Masudrad M. Galvanic corrosion of and ion release from various orthodontic brackets and wires in a fluoride-containing mouthwash. J Dent Res Dent Clin Dent Prospects 2015;9(3):159.

14. Rafeeq RA, Saleem AI, Nissan LMK. Ions release from fixed orthodontic appliance in two different mouthwashes. J Bagh Coll Dentistry 2014;26(4):152-155.

15. Park HY, Shearer TR. In vitro release of nickel and chromium from simulated orthodontic appliances. Am J Orthod 1983; 84(2):15615-15619.

16. Hwang CJ, Shin JS, Cha JY. Metal release from simulated fixed orthodontic appliances. Am J Orthod Dentofacial Orthop 2001;120(4):383-391. 
17. Gandini P, Orsi L, Bertoncini C, Massironi S, Franchi L. In vitro frictional forces generated by three different ligation methods. Angle Orthod 2008;78(5):917-921.

18. Kusy RP, Whitley JQ, Prewitt MJ. Comparison of the frictional coefficients for selected archwire-bracket slot combinations in the dry and wet states. Angle Orthod 1991;61(4): 293-302.

19. Kahlon S, Rinchuse D, Robison JM, Close JM. In vitro evaluation of frictional resistance with 5 ligation methods and Gianelly-type working wires. Am J Orthod Dentofacial Orthop 2010;138(1):67-71.

20. Redlich M, Mayer Y, Harari D, Lewinstein I. In vitro study of frictional forces during sliding mechanics of "reducedfriction" brackets. Am J Orthod Dentofacial Orthop 2003; 124(1):69-73.

21. Stefanos S, Secchi AG, Coby G, Tanna N, Mante FK. Friction between various self-ligating brackets and archwire couples during sliding mechanics. Am J Orthod Dentofacial Orthop 2010;138(4):463-467.

22. Nanjundan K, Vimala G. Evaluation of frictional resistance and surface characteristics after immersion of orthodontic brackets and wire in different chemical solutions: A comparative in vitro study. Indian J Dent Res 2016;27(5): 513-520.

23. Eliades T, Brantley WA. Orthodontic application of biomaterials-A clinical guide. 1st ed. Amsterdam: Woodhead Publishing; 2017.

24. Danaei SM, Safavi A, Roeinpeikar SM, Oshagh M, Iranpour $\mathrm{S}$, Omidkhoda M. Ion release from orthodontic brackets in3 mouthwashes. Am J Orthod Dentofacial Orthop 2011; 139(6):730-734

25. Yanase $Y$, Ioi H, Nishioka M, Takahashi I. Effects of sliding velocity on friction: An in vitro study at extremely low sliding velocity approximating orthodontic tooth movement. Angle Orthod 2014;84(3):451-458.
26. Mohammed AA. Evaluation and comparison of frictional forces generated by three different ligation methods. A master thesis, Department of Orthodontics, College of Dentistry, University of Baghdad, Iraq, 2010.

27. Nahidh M, Garma NM, Jasim ES. Assessment of ions released from three types of orthodontic brackets immersed in different mouthwashes: An in vitro study. J Contemp Dent Pract 2018;19(1):73-80.

28. Charng T, Lansing F. Review of corrosion causes and corrosion control in a technical facility. TDA Progress Report, USA, 1982. pp. 145-156.

29. Miyakawa Y. Friction and wear performance of gold and gold alloy films. Gold Bull 1980;13(1):21-30.

30. Choi SH, Kang DY, Hwang CJ. Surface roughness of three types of modern plastic bracket slot floors and frictional resistance. Angle Orthod 2014;84(1):177-183.

31. Mandsaurwala M, Kalia A, Gupta G, Hegde A, Mirdehghan N. Comparative evaluation of ion release from orthodontic mini-implants in 2 mouthwashes. Int J Oral Health Dent 2015; 1(4):177-181.

32. Singh RK. Corrosion protection of stainless steel in vegetables by Aloe Vera juice. Int J Appl Engineering Technol 2012;2(3): 28-35.

33. Alavi S, Farahi A. Effect of fluoride on friction between bracket and wire.Dent Res J (Isfahan) 2011;8(Suppl 1):S37-S42.

34. Huang HH. Variation in surface topography of different NiTi orthodontic archwires in various commercial fluoridecontaining environments. Dent Mater 2007;23(1):24-33.

35. Alavi S, Hosseini N. Load-deflection and surface properties of coated and conventional superelastic orthodontic archwires in conventional and metal-insert ceramic brackets. Dent Res J (Isfahan) 2012;9(2):133-138.

36. Mangaiyarkarasi SP, Manigandan T, Elumalai M, Cholan PK, Kaur RP. Benefits of Aloe Vera in dentistry. J Pharm Bioallied Sci 2015; 7(Suppl 1): S255-S259. 